\title{
Use of Local and Nonconventional Raw Sources in Technology of Preparation of Emulsion
}

Azim Oltiev* and Sulaymanova GH

Bukhara Engineering-Technological Institute, Bukhara, Republic of Uzbekistan

“Corresponding author: Azim Oltiev, Bukhara Engineering-Technological Institute, Bukhara, Republic of Uzbekistan, Tel: +998936587818; E-mail: azim-10-86@mail.ru Received date: March 18, 2016; Accepted date: October 28, 2016; Published date: October 30, 2016

Copyright: (c) 2016 Oltiev A, et al. This is an open-access article distributed under the terms of the Creative Commons Attribution License, which permits unrestricted use, distribution, and reproduction in any medium, provided the original author and source are credited.

\begin{abstract}
The butter on its taste-aromatic properties is the quality standard for the majority of types of emulsion fat-and-oil products intended for the technological purposes and direct use in food. Recently majority technological and inexpensive components of compounding of fatty emulsion have superseded traditional raw components. Despite that, reference taste and aroma fatty emulsion product still are traditional notes of sour-creamy and sweet-butter.
\end{abstract}

Keywords: Aromatic; Carbohydrate; Aroma

\section{Introduction}

The substances directly participating in creation of specific taste and smell of butter are formed as a result of transformations of carbohydrates, amino acids and butterfat at technological processing (heating, souring, maturing, pasteurization etc.) and storage $[1,2]$. Group of carbonyl compounds, carbon acids, lactones, amino compounds, etc. is concern to them.

\section{Purpose of Work}

Research of basic physical and chemical characteristics of fatty emulsion, including on basis of milk processing products.

\section{Course of Research}

In emulsion fatty dairy products are found out aldehydes (formaldehyde, acetaldehyde, propionic, butyric, isobutyric, valerian, isovalerian, capronic, caprylic, crotonic, etc.), ketones (acetone, acetylmethylcarbinol, diacetyl, butanon-2. geptanon-2 etc.) [3].

To the major components of taste and a smell of fatty emulsion concern first of all dairy (dairy emulsions) and volatile fat acids: ant, acetic, propionic, butyric, capronic, caprylic, caprinic, etc. On Figure 1 is cited the data of chromatography analysis of volatile fat acids of dairy fatty emulsion.

Volatile fat acids have strongly expressed smell and taste: C1-C4irritating, sharp, C4-C10-unpleasant rancidity, musty, knitting. At strong dilution some of them have weak pleasant (creamy, oil etc.) taste and smell.

Lactones are the important components of smell of dairy fatty emulsion. There are allocated and identified sated and non-saturated and lactones of aliphatic acids with number of carbon atoms from 6 to 20. According to the data chromatographic analysis of dairy fatty emulsion (Figure 2), prevail - and -lactones with even number of carbon atoms, the others contain in smaller quantities.

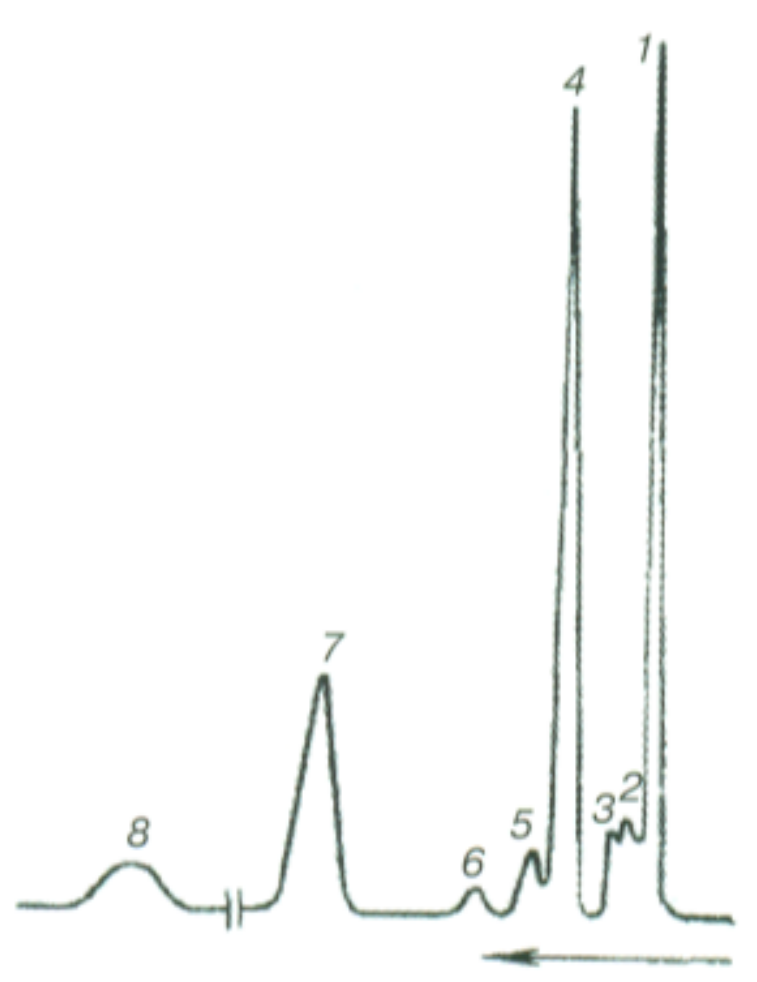

Figure 1: Chromatogram of volatile fat acids of dairy fatty emulsion (1 - acetic, 2-propionic, 3-isoleic 4 - butyric, 5 - isovaleric, 6 valeric, 7-capronic, 8 - caprylic). 
Page 2 of 3

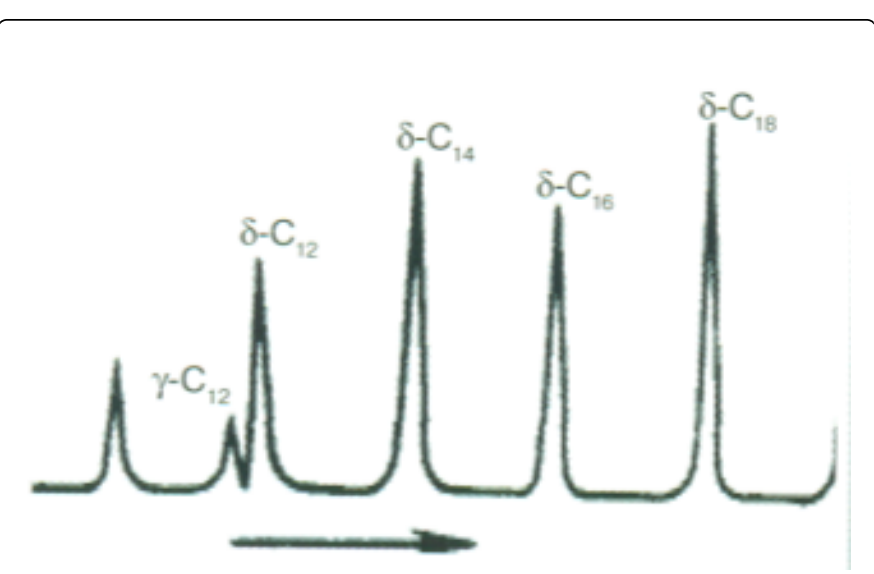

Figure 2: Chromatogram lactones dairy fatty emulsion.

Aroma-forming properties of lactones depend on their structure and concentration. In small concentration lactones possess pleasant taste and smell of cream, vegetable oils and fats. At the high maintenance some of them can give to products undesirable smacks stale, oils and fats, etc. Maintenance of lactones in dairy fatty emulsion depends including on modes of thermal processing, because with increase in temperature of pasteurization their concentration raises.

Hydrogen sulfide, dimethyl sulfide, dimethyl disulfide in small concentration is necessary compounds for creation of the balanced aroma of dairy fatty emulsion.

\section{Results and Discussions}

Various combinations of mentioned above aroma-forming compounds allow to model taste and aroma of dairy fatty emulsion received on various technological schemes.

The maintenance of taste and aroma substances in natural dairy fatty emulsion fluctuates depending on mode of thermal processing of dairy fatty emulsion, temperatures and durations, modes and periods of storage of products and other technology factors. On an example of dairy fatty emulsion oils we can consider influence of way of reception emulsion on the maintenance of taste and aroma substances (Table 1).

\begin{tabular}{|l|l|l|l|}
\hline \multirow{2}{*}{ Way of emulsion reception } & \multicolumn{2}{l|}{ The maintenance of aromatic substances (mg\%) } \\
\cline { 2 - 4 } & Diacetyl & Ethers fatile fat acids (in recalculation on acetic \\
\hline Churning & 0.12 & 1.9 & 5.6 \\
\hline Transformation of high fats of dairy fatty emulsion & & & \\
\hline Without biochemical maturing of dairy fatty emulsion & 0.15 & 2.3 & 5.6 \\
\hline With biochemical maturing of dairy fatty emulsion & 0.24 & 3.6 & 7.3 \\
\hline
\end{tabular}

Table 1: Aromatic substances of dairy-fatty emulsion at technological processing.

Clear marked specific taste and smell of dairy fatty emulsion of oils are caused by diacetyl, lactic acid, volatile fat acids (among which acetic acid makes about 70\%), acetaldehyde and some lactones.

The main components of taste and smell of dairy fatty emulsion are sulphurous compounds, 5-lactones and volatile fat acids. For this category of emulsion specific smack especially expressed in emulsion is characteristic. Taste of dairy fatty emulsion supplemented with small amounts of lactones formed at thermal processing (6-deca and 5dodecalactone), diacetyl, methylketone (butanon-2. etc.) and some other ketones and aldehydes.

The obtained data has formed a basis for modelling of organoleptic properties of dairy fatty emulsion identical on taste-aroma properties to the reference product: sour-creamy and sweet-creamy butter.

The task in view is to expand assortment of aromatizer of "Dairy butter" series allowing to model taste and aroma of reference fatty basis.

For the analysis of taste-aroma properties of flavoured fatty products were used organoleptic methods. Tool methods of the analysis of aroma applied now do not give representation about complex influence of all aromatic substances on organoleptic indicators of product. Chromatographic methods of the analysis in some cases allow estimating the maintenance of main by quantity components. Sensor methods of the analysis allow estimating thousand shades of a smell and taste of products.

Organoleptic analysis was carried out by profile method. Intensity of a sign characterized on a five-point scale. The most significant aromatic notes have been defined on the basis of processing of tasting results $[4,5]$.

On Figure 3 resulted the sensor diagram of aroma of emulsion fatty product prepared with aromatizer "Dairy butter".

Organoleptic profile of flavoured emulsion fatty products is close enough to the reference sample. The choice of optimum parity of aroma-forming substances in finished emulsion fatty product has allowed solving a task in view. 
Citation: Oltiev A, Sulaymanova GH (2016) Use of Local and Nonconventional Raw Sources in Technology of Preparation of Emulsion. J Exp Food Chem 2: 117. doi:10.4172/2472-0542.1000117

Page 3 of 3
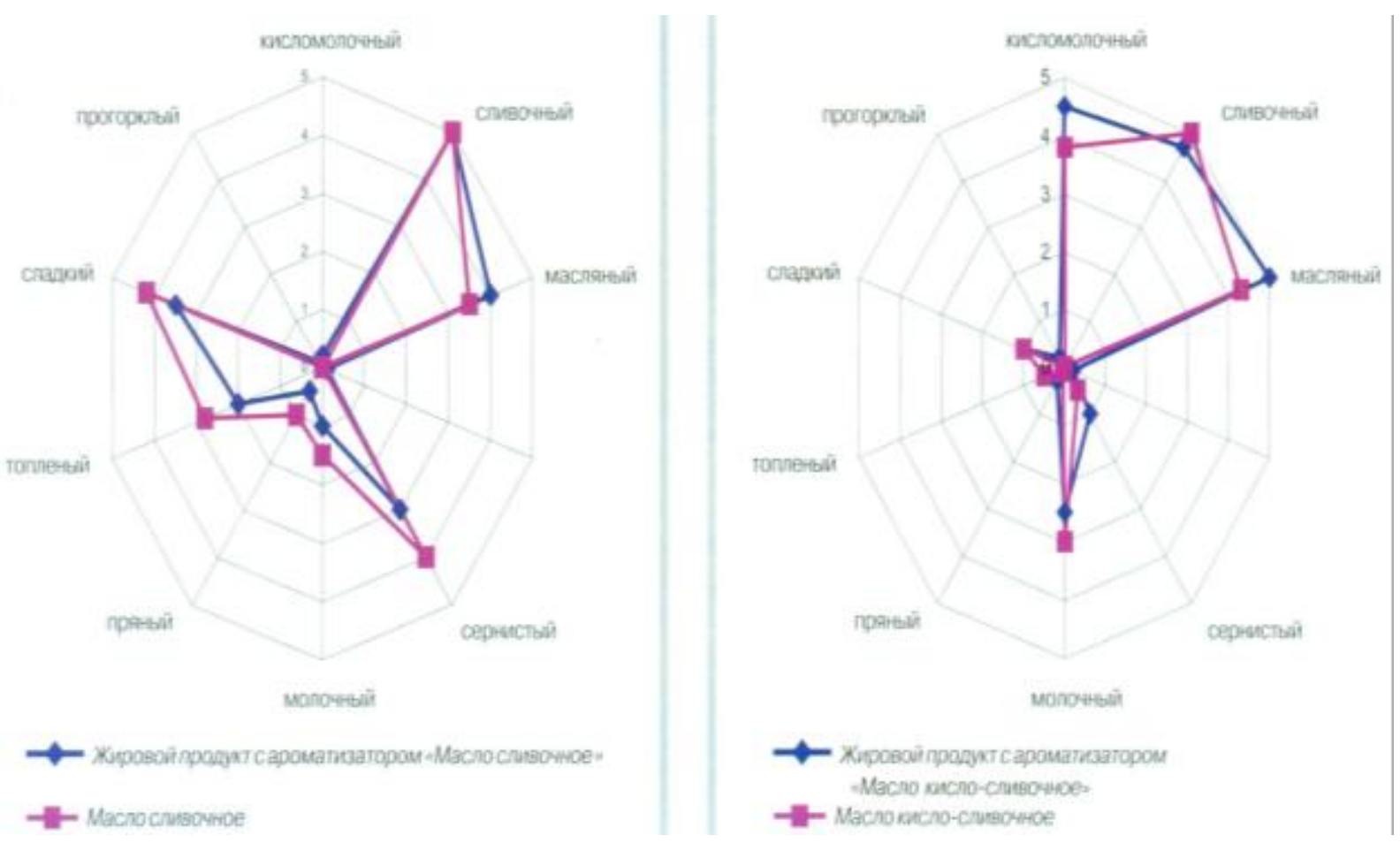

Figure 3: Showing sensor diagram of emulsion fatty product.

\section{Conclusion}

Research of the basic characteristics of fatty emulsions has allowed to expand assortment of products on their basis and to establish the basic directions of management of organoleptic properties of fat-andoil production.

\section{References}

1. Rudakov OB, Vostrov IA, Fedorov SV, Filipov AA, Selemenev VF, Pridantsev AA (2004) "Guide of chromatographer" Voronezh.

2. Cazes J, Scott RPW (2002) "Chromatography theory" New York.
3. Tereshuk LV (2006) Dairy-fatty composition: Kemerovo technological institute of food industry-Kemerovo; 2006. p. 209.

4. Polyanskiy KK, Snegiryov CA, Rudakov OB (2004) Differential thermal analysis of food fats. M Deli; 2004. p. 85.

5. Arutyuyan NS, Kornena EP, Yanova LI (1999) Technology of fat processing. M Pishepromizdat, p. 452.

6. Kornena EP, Kalmanovich SA, Martovshuk EV (2007) Expertise of oils, fats and their products. Edited by Pozdnyakovskiy VM-Novosibirsk; 2007. p. 272.

7. Sulaymanova GH, Majidov KH (2015) Stabilizers and emulsifier of lowfat butter production / "Uzbek chemical journal" Tashkent; 2015. pp. 76-79. 